\title{
Proceeding
}

10th INSHS International Christmas Sport Scientific Conference, 4-5 December 2015. International Network of Sport and Health

Science. Szombathely, Hungary

\section{Changes in speed and efficiency in the front crawl swimming technique at $100 \mathrm{~m}$ track}

\author{
JAN STASTNY , JAROSLAV MOTYCKA, MICHAELA BATOROVA, MILAN PASEK \\ Centre of Sport Activities, Brno University of Technology, Brno, Czech Republic
}

\begin{abstract}
The aim of our research is to show how the speed of competitive swimmers at a $100 \mathrm{~m}$ track $(4 \times 25 \mathrm{~m})$ develops and to find out if there are any considerable changes in swimming efficiency. As for the speed, we expect its gradual decrease caused by fatigue. Efficiency of swimming is directly determined by mastering of swimming techniques. However the question is whether it is also influenced by fatigue. It expands our earlier publications and includes measurements conducted not only at the $50 \mathrm{~m}$ swimming track (two sections $/ 25 \mathrm{~m}$ legs) but also those taken at the $100 \mathrm{~m}$ track (four sections $/ 25 \mathrm{~m}$ legs). Thanks to our measuring device called Tachograph, we have been able to record and subsequently analyse the results of 10 male and seven female swimmers, all being between the ages of 18 and $23 / 26$. Research shows that the average mean speed in male categories declines from $1.65 \mathrm{~m}^{*} \mathrm{~s}^{-1}$ reached in the first section down to $1.50 \mathrm{~m}^{*} \mathrm{~s}{ }^{-1}$ in the fourth section. The decrease seems to be linear during the first three sections while it is not so significant in the fourth swimming legs. Efficiency of swimming slightly decreases from 0.949 to 0.936 . As for the female swimmers, their average mean speed decreases from $1.46 \mathrm{~m}^{*} \mathrm{~s}^{-1}$ (measured in the first section) to $1.34 \mathrm{~m}^{*} \mathrm{~s}^{-1}$ in the fourth section. The decline is more or less linear, with a slight reduction in value. Efficiency has a subtle declining tendency (from 0.967to0.961). In both male and female categories, the speed of swimming slightly declines, whereas changes in the efficiency of swimming are not substantial. Key words: TACHOGRAPH; FREESTYLE; SWIMMER, FATIGUE.
\end{abstract}

Corresponding author. Centre of Sport Activities, Brno University of Technology, Technická 2896/2, 61669 Brno, Czech Republic E-mail: stastny@cesa.vutbr.cz

10th INSHS International Christmas Sport Scientific Conference, 4-5 December 2015. International Network of Sport and Health Science. Szombathely, Hungary.

JOURNAL OF HUMAN SPORT \& EXERCISE ISSN 1988-5202

(C) Faculty of Education. University of Alicante

doi:10.14198/jhse.2016.11.Proc1.07

VOLUME 11 | Proc1 | 2016 | S168 


\section{INTRODUCTION}

Our research focuses on changes and development in speed and efficiency of front crawl swimming technique of competitive swimmers. Measurements are conducted with the help of the measuring system Tachograph. The aim of our research is to show how the speed of swimmers at a $100 \mathrm{~m}$ track $(4 \times 25 \mathrm{~m})$ develops and to find out if there are any considerable changes in swimming efficiency. As for the speed, we expect its gradual decrease caused by fatigue; however the efficiency of swimming is directly determined by mastering of swimming technique, which we cannot predict. The research is based on our previous investigations of measurements conducted at the $50 \mathrm{~m}$ swimming track (two sections/ $25 \mathrm{~m}$ legs) but also those taken at a $100 \mathrm{~m}$ track (four sections/ $25 \mathrm{~m}$ legs).

When monitoring the results at the $50 \mathrm{~m}$ track, it was found out that in the second section there is a slight decrease in the efficiency of swimming technique and a statistically significant decrease in swimming speed. (Motycka \& Stastny \& Lepkova \& Pasek, \& Batorova, 2013).

Our research questions are as follows:

1) Is the efficiency of swimming influenced by fatigue?

2) Does the decrease in speed between the measured sections have a linear progression, or is it different?

3) What are the differences in the concept of male and female swimming in terms of speed and efficiency of swimming technique?

\section{MATERIAL AND METHODS}

\section{Participants}

The research sample was composed of 10 men and 7 women. They all are competitive swimmers in the freestyle discipline, they are members of the competitive teams in the Czech Republic, and in terms of their age they fall into the category of seniors (adults).

Age categories:

10 men, 18 - 23 years (avg. 19.8; s. dev. 1.9)

7 women, $18-26$ years (avg. 20.5; s. dev. 3.0)

\section{Measurements}

Measurements are conducted with the help of the measuring system Tachograph developed by our team. The system records the instantaneous speed of swimmers, from which the software calculates the mean speed in the evaluation of swimming at a specified interval, further the efficiency of swimming technique and other variables. Simultaneously with speed recordings, the data from three cameras mounted beneath the surface are synchronously stored. With the help of the recordings from the cameras, we can set the measured section suitable for evaluation. We evaluate the section of swimming at the surface, without the influence of take-off and touch of swimmers. The interval starts simultaneously with the second stroke of the swimmer with the arm transfer above the surface. At this instant, the speed of the swimmer is already stable. The end of the interval is set two meters before the end of each section.

\section{Procedures}


Measurements were carried out between the years 2010 and 2015, always by a team of the same six researchers. Measurements are carried out in the same $25 \mathrm{~m}$ - long pool with high-quality conditions ensured for our team. Annually, from six to eight separate measurements are taken.

Prior to testing, the swimmers have sufficient time to heat; the order of testing is as follows: 1. front crawl interplay, 2. front crawl legs (kicks), 3. front crawl arms.

\section{Analysis}

Data from measurements are evaluated by the software SwimDatabase, which is used to select the data for subsequent processing. In this case, these are the data obtained from the $100 \mathrm{~m}$ swimming style crawl interplay. These data are evaluated in SW SwimDataViewer. For each selected measurement we set the respective intervals to calculate the variables of mean speed, efficiency, etc. for each track section.

SW SwimDataViewer calculates the results using the formulas shown in Fig.1.

$$
\begin{aligned}
& \text { mean speed }\left(\mathrm{m}^{*} \mathrm{~s}^{-1}\right) \text { : } \\
& \qquad \bar{v}=\frac{\sum_{i=1}^{n} v_{i}}{n} \\
& \text { efficiency of swimming technique }(\%) \text { : } \\
& \qquad \eta=\frac{\text { work at uniform speed (lower) }}{\text { work at real speed (higher) }}=\frac{k \bar{v}^{3} t}{k \Delta t \sum_{i=1}^{n} v_{i}^{3}}
\end{aligned}
$$

Figure 1. Formulas (Motycka \& Stastny \& Lepkova \& Pasek, \& Batorova, 2013)

Calculations show that:

"Efficiency of swimming technique is calculated from the work done while swimming. It is the work at uniform speed divided by actual work corresponding to the measured actual variable speed."(Motycka \& Stastny \& Lepkova \& Pasek, \& Batorova, 2013)

Swimming with minor variations in speed is less energy consuming (less effort is needed), swimming technique is therefore more efficient.

These data are converted to the MS Excel table for further processing. Based on the criteria (age, sex, date of testing, etc.), the data are filtered for further processing in the program Statistica 12.

\section{RESULTS}

\section{Men}

The results show that the highest mean swimming speed is achieved in the first section. Speed decreases up to the fourth section.

Values of mean speeds in the sections $1-4: 1.65 ; 1.58 ; 1.51 ; 1.50 \mathrm{~m}^{*} \mathrm{~s}^{-1}$ 


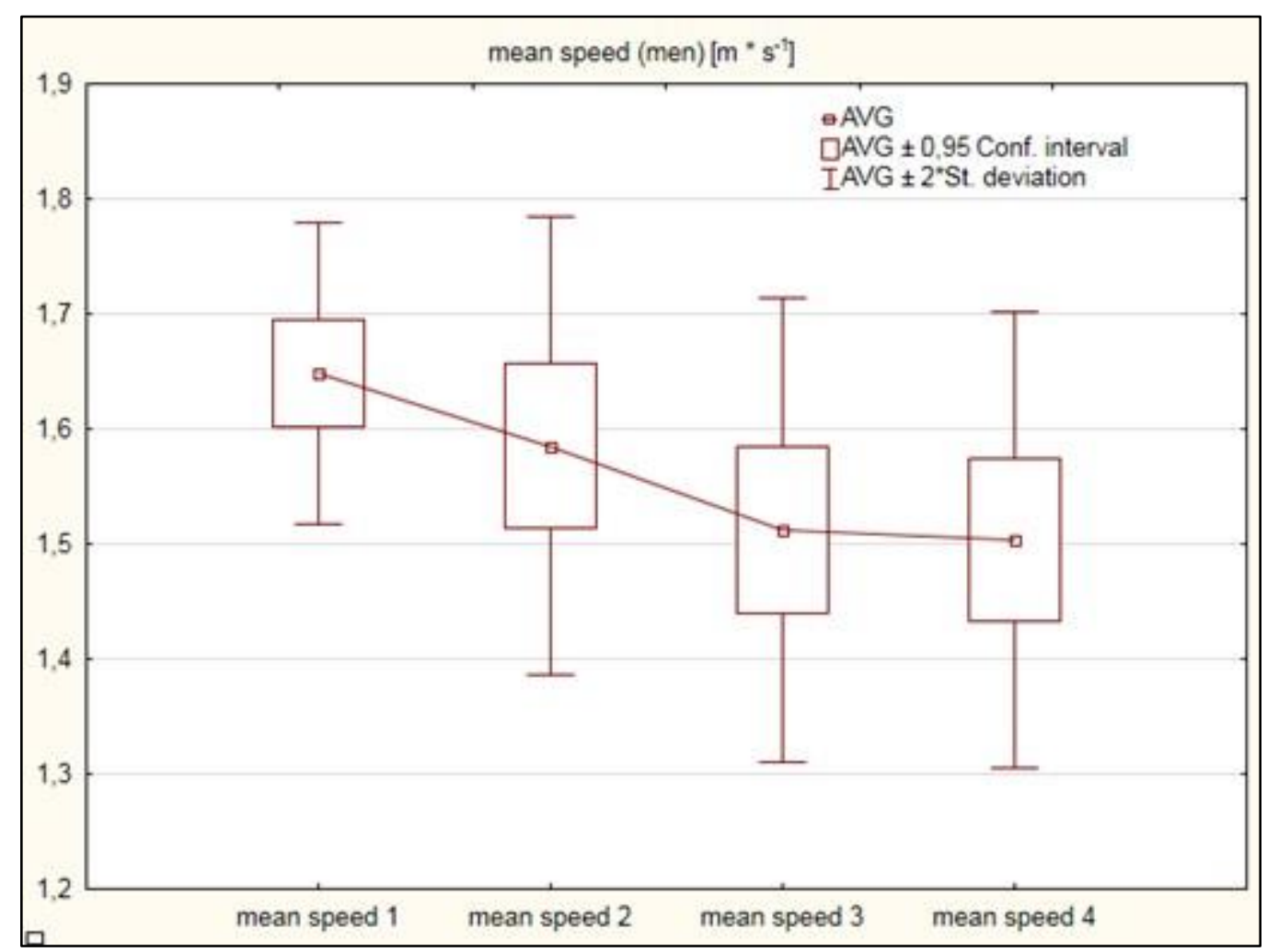

Figure 2. Mean speed (men)

Swimming efficiency is the highest in the first section. The lowest value is reached in the third section.

Values of efficiency in the sections $1-4: 0.949 ; 0.942 ; 0.931 ; 0.936$ 


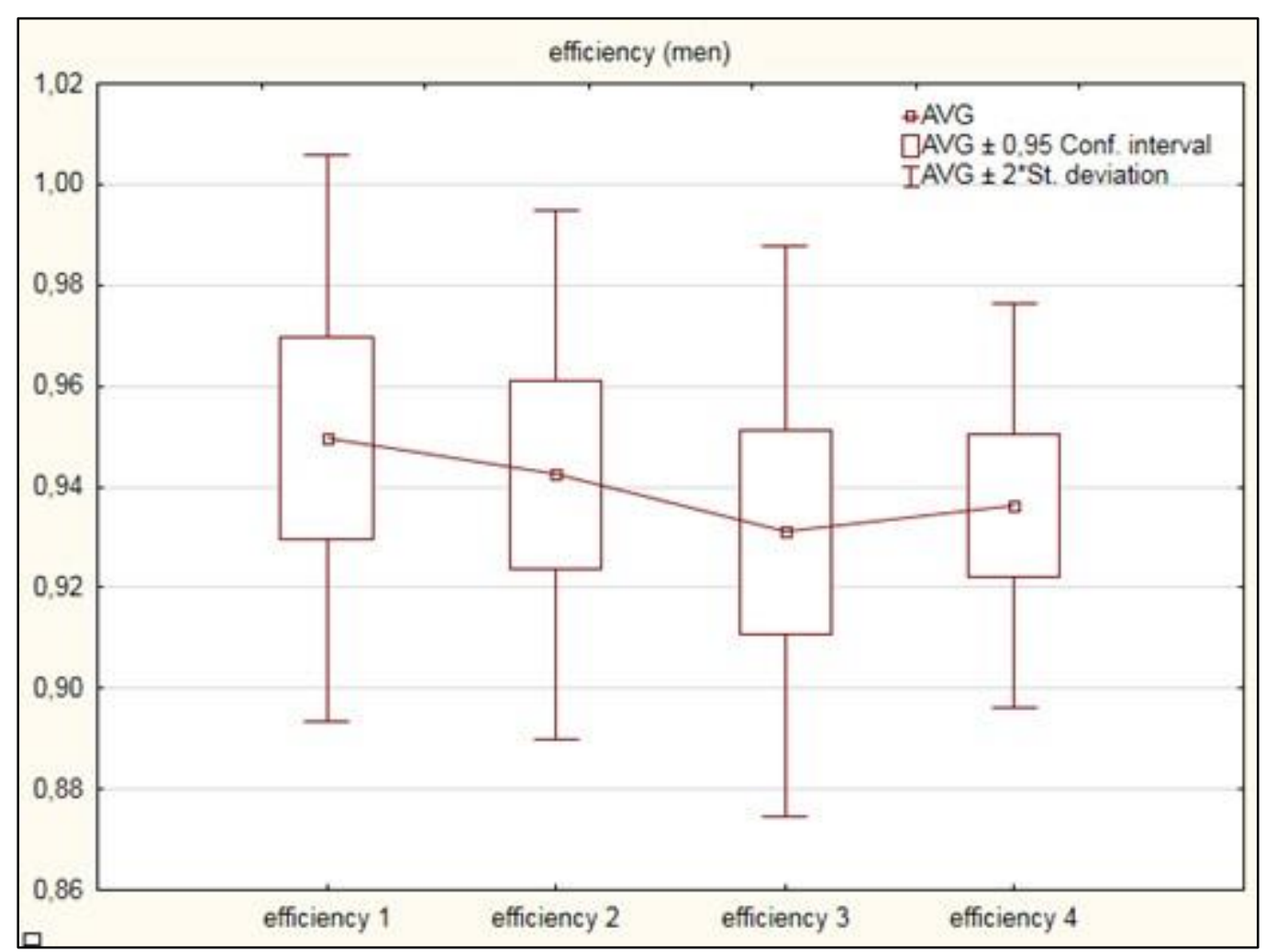

Figure 3. Efficiency (men)

\section{Women}

Mean speed in the women's category is also the highest in the first section of swimming track, while in other sections it gradually decreases. The decline is more or less linear with a slight reduction in value.

Values of mean speed in the sections $1-4: 1.46 ; 1.40 ; 1.37 ; 1.34 \mathrm{~m}^{*} \mathrm{~s}^{-1}$ 


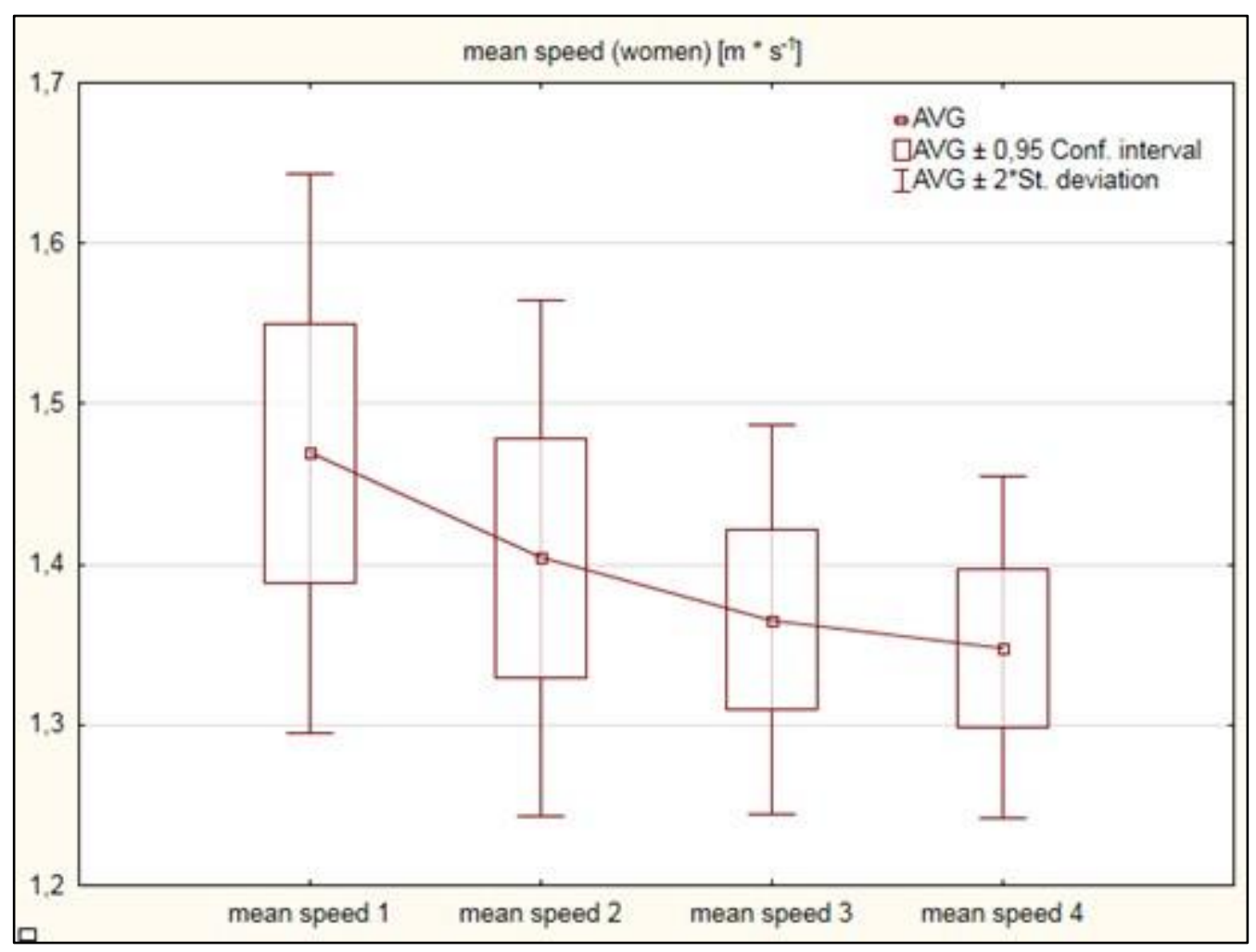

Figure 4. Mean speed (women)

Swimming efficiency of women is the highest in the first section; the lowest, similarly to men, in the third section.

Values of efficiency in the sections 1 - $4: 0.967 ; 0.966 ; 0.956 ; 0.961$ 


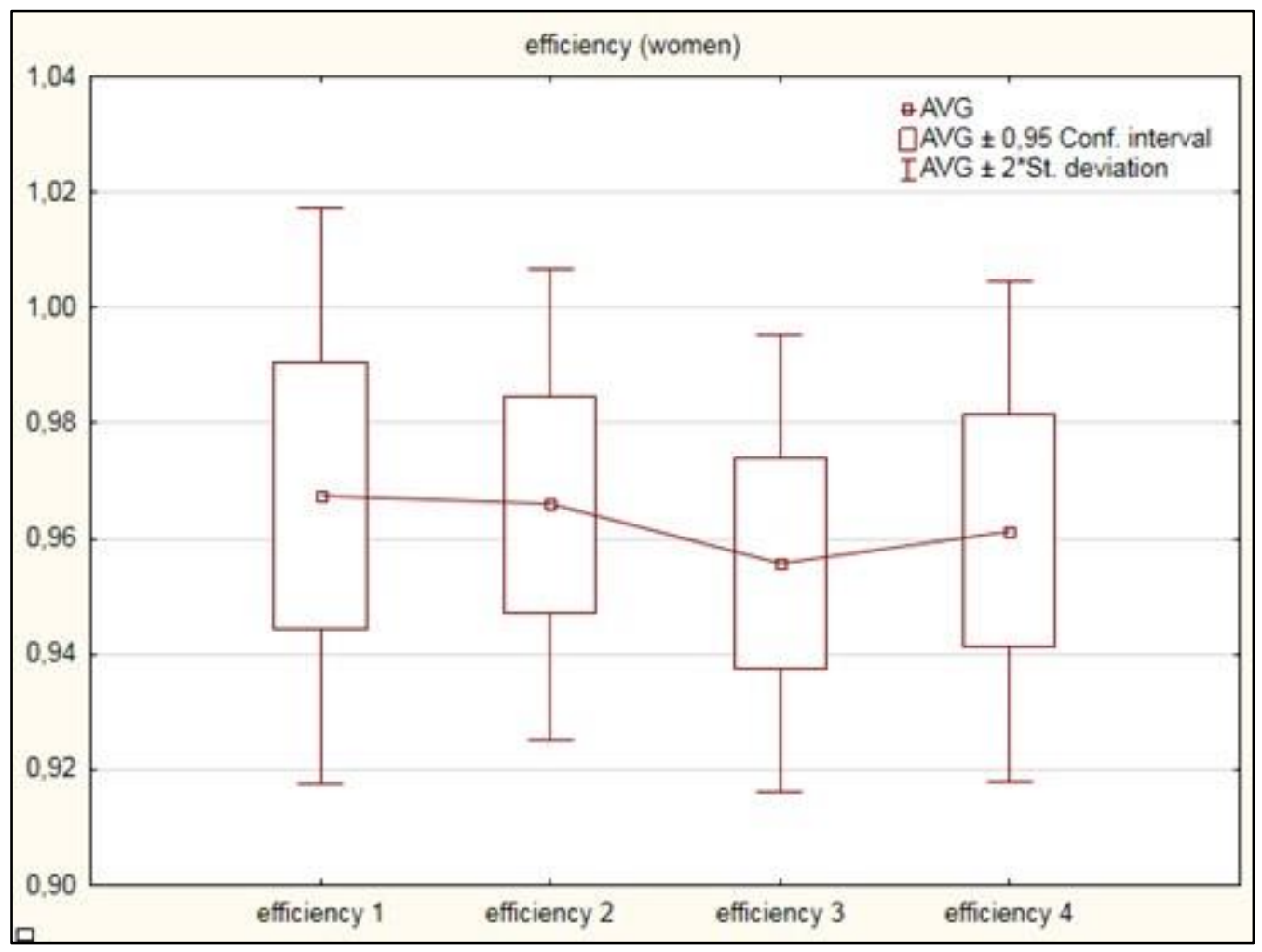

Figure 5. Efficiency (women)

\section{DISCUSSION}

\section{Mean speed}

We found out that in both male and female categories the speed of swimming declines nearly linearly in the first three sections. In the last section (fourth swimming legs), the decline in speed is insignificant. In the fourth section, the swimmers maintain their speed almost unchanged.

For women, the mean swimming speed decreases in all sections; however the trend of speed decrease is not completely linear (it is rather semi-logarithmic).

Therefore the changes in mean speed in the last section are not caused only by fatigue but they can also be influenced by tactics, motivation, and distribution of power over the entire track.

\section{Efficiency}

In the case of efficiency, for both men and women, were recorded the highest level in the first section, the lowest in the third section, and in the fourth section we can see another increase. For both categories, the efficiency graphs are very similar. In the case of men, it can be observed that the development of efficiency replicates the course of mean speed in each section.

A hypothesis of influence of fatigue on the efficiency of swimming technique cannot be confirmed. Efficiency is used as an indicator of mastering of swimming technique.

\section{Differences men - women}


The category of men differs from that of women by higher mean speed in all measured sections.

The differences in the efficiency of individual sections are insignificant. However, the development of efficiency in both categories has a similar character. In female category, we can observe higher levels of efficiency achieved.

The results of efficiency and speed support the theory that men swim using more power, while the power capabilities of women are replaced by more efficient swimming technique.

\section{Comparison to the previous research}

Compared with the previous research (Štastný, \& Motyčka, 2014) at shorter tracks (50m long), we managed to prove that at the doubled track the development of efficiency is uneven. There are subtle declines but the value varies. The speed at the 50-meter section was decreasing; however the measurements over a longer track brought about more detailed results. Over the 100-m track, we found out that the decrease in mean speed is not fully linear. Apart from fatigue, it is also influenced by tactics and distribution of power.

The study is limited by a relatively low number of swimmers; it evaluated only the section without the effect of take-off and turns. With swimmers, we do not evaluate their current fitness, health condition, and level of motivation.

\section{CONCLUSIONS}

We dealt with monitoring of mean speed and efficiency of swimming style crawl of competitive swimmers at the $100 \mathrm{~m}$ track. We were interested in the values of these variables in the individual sections of the track and their development.

The mean speed of swimming declines in all sections except for the last one where the decline stops. It is evident that other factors, not only fatigue, are involved in here.

Development of swimming technique efficiency is uneven; changes are relatively slight, and the impact of fatigue is not confirmed.

Differences in the concept of swimming of men and women are evident as based on the results of speed and efficiency. Men reach higher speeds but lower efficiency of swimming technique than women. This can be attributed to more powerful swimming of men compared to more technical swimming of women.

In the future, our intention is to measure and evaluate a larger group of swimmers at the $100 \mathrm{~m}$ freestyle. Sufficient data should be also collected to compare the age categories.

\section{REFERENCES}

1. Motycka, J., Stastny, J., Lepkova, H., Pasek, M., \& Batorova, M. (2013). Kinematic and dynamic analysis of swimming 2009-2013. Sport and quality of life, 14-24.

2. Št'astný, J., \& Motyčka, J. (2014). Changes in mean swimming speed and efficiency in the front crawl at $2 \times 25 \mathrm{~m}$ track. Szombathely. 